\title{
EL RÍO: UN PROTAGONISTA OCULTO EN EL DIÁLOGO DE LAS AGUAS
}

\author{
o rio: um protagonista oculto no dialogo das aguas
}

\author{
Nubia Caramello * \\ David Saurí **
}

\begin{abstract}
Resumo
Com esse artigo pretendemos identificar como o rio tem sido contextualizado em alguns diálogos ambientais relevantes levados a cabo nos séculos XX e XXI, e como há alterado alguns rios de relevância mundial, regional ou local. O objetivo principal foi identificar a possibilidade de converter essa história do ambiente hídrico em um instrumento aplicável no gerenciamento das águas fluviales. Metodologicamente é um estudo qualitativo, foi realizado uma análise de conteúdos obtida de fontes: taxonómico, diplomáticas, visuais e orales. Concluise que a história ambiental dos rios e a interação com a bacia hidrografica que faz parte pode ser convertido em um indicador a ser utilizado para evidenciar a relação dos rios e das mudanças ambientais onde estão localizados, identificando seu protagonismo na historia dos povos e dos ambientes onde estão inseridos.
\end{abstract}

Palavras-chave: Dialogo Hidrico; Gestão das Aguas; Rios; Historia Ambiental.

\begin{abstract}
The aim of this article is to highlight the role of the rivers in relevant environmental dialogues of the XX and XXI centuries, identifying how the river is contextualized in the dialogues regarding water worldwide and how much some of the rivers of world, regional and local relevance have changed in the same period. The main goal is to identify the possibility to convert the history of the water environment into an applicable instrument for the fluvial water management. To this, an analysis of different taxonomic, diplomatic, visual and oral sources was carried out. From the analysis, it was possible to conclude that the environmental history of rivers and their interaction with the river basin where they are inserted can be interpreted as indicators of the relation of rivers with existing broader environmental changes, identifying them as protagonists in the history of the people and of their villages and cities of residence.
\end{abstract}

Key words: Water dialogue; Water Management; Rivers; Environmental History.

\section{Resumen}

Con ese artículo se pretende evidenciar el papel del Río en ciertos diálogos ambientales relevantes llevados a cabo durante los siglos XX y XXI, contextualizándolo en el diálogo mundial de las aguas, para evidenciar cómo han cambiado algunos ríos - de relevancia mundial, regional o local - en el mismo periodo. El objetivo principal trata de identificar la posibilidad de convertir esa historia hídrico-ambiental en un instrumento aplicable a la gestión de las aguas fluviales. Para ello se realizó un análisis de diferentes fuentes: taxonómicas, diplomáticas, visuales y orales. Así fue posible concluir que la historia ambiental de los ríos, junto a la interacción con la cuenca de la que forman parte, pueden convertirse en un indicador de la relación entre los ríos y los cambios ambientales en los cuales están inmersos, identificando su protagonismo en la historia de los pueblos como en la historia de los ambientes en los que están ubicados.

Palabras claves: Diálogo hídrico; Gestión de las Aguas; Ríos; Historia Ambiental.

(*) Doctoranda en Geografía del Programa de Pos Graduación en Geografía en la Universidad Autónoma de Barcelona - Departamento de Geografía. Facultad de Letras, 08193 Bellaterra (España), Despacho: B9/1102, Tel: (+34 93) 5811515 nubiacaramello@yahoo.com.br.

(**) Prof. Dr. en la Universidad Autónoma de Barcelona - Departamento de Geografía. Facultad de Letras, 08193 Bellaterra (España). Tel:: (+34 93) 5811515 - david.sauri@uab.cat. 


\section{INTRODUCCIÓN}

El agua dulce es un elemento preciado disponible en la naturaleza y reconocido por las organizaciones internacionales como un bien natural de derecho global para todos los pueblos. La ausencia de una gestión integrada de recursos hídricos no hace sino agravar la irregular distribución espacial - de origen natural - del pequeño porcentaje de agua dulce disponible en el planeta (alrededor del $3 \%$ del total), comprometiendo a los más de 7000 millones de habitantes, de los cuales alrededor de 700 millones no tienen acceso al agua potable y casi 2000 millones no cuentan con saneamiento suficiente. De ahí que casi un millón y medio de personas mueran actualmente por enfermedades vinculadas al agua en el momento que escribimos ese texto (WORLDOMETERS, 2015).

Entre las formas de acceso al agua como recurso se subrayan la apropiación directa de las aguas superficiales ubicadas en lagos y ríos, la extracción de las aguas subterráneas (a través de la exploración de acuíferos) y la desalinización del agua del mar. Sin embargo, las dos últimas no están disponibles en todos los países y el acceso a esas alternativas está vinculado a las estructuras económicas, sociales, culturales y tecnológicas, así como a las políticas públicas específicas de cada territorio, que pueden comprometer el acceso al agua y saneamiento de los menos favorecidos económicamente. Todo ello justifica su inserción en un enfoque de diálogos ambientales en escalas diferenciadas, en busca de una propuesta eficiente de gestión de las aguas.

En este proceso es relevante recordar que la tradicional obtención del agua dulce ha convertido a gran parte de los ríos en protagonistas del desarrollo histórico de muchos pueblos, entre los que citaremos en el presente texto dos referentes universales como el Nilo y el Rin. A nivel regional y en relación con el presente trabajo, podríamos citar el Guaporé, el Vermelho, los ríos Branco y Colorado (Rondônia/Brasil), el Muga, el Tordera, el Valle d'Ozinelles (región de la Cataluña/ España); el Maturraña (cuenca del Ebro/España) y los afluentes de la margen derecha del río Amazonas (Xingu, Tapajós, Madeira, Puruá, Jutaí y Javari). Muchos de ellos han permanecido ocultos en gran parte de los diálogos y debates so-bre las aguas.

Partimos del hecho de que un río está insertado en un territorio del que forma parte, por lo que es posible identificar su contexto histórico y geográfico. Igualmente el río registra las consecuencias de la gestión territorial - o bien la ausencia de ella - por lo que puede estudiarse como un registro histórico de los cambios ambientales a lo largo de las relaciones entre su ciclo hidrológico y la sociedad actual o las sociedades que allí han vivido en tiempos pretéritos.

De acuerdo con Boff (2009), actualmente vivimos una situación inédita: una "guerra colectiva" contra Gaya. Atacamos la Tierra en todos sus frentes: en suelo y subsuelo, en el aire, en las selvas, en las aguas, en los océanos. Todo ello con el objetivo de una "satisfacción de desarrollo" que se yuxtapone a un teórico "desarrollo sostenible" mundial. Para Saurí y Boada (2002) los cambios ahora necesitan dotarse de una ética socioambiental global que posibilite nuestra propia supervivencia.

Lo cierto es que heredamos una metodología del desarrollo económico plagada de malos usos y externalidades negativas que afectan a las aguas superficiales, otrora abundantes y que hoy se han convertido en no aptas para el consumo in natura. Por otro lado se abandonan los ríos y crece el abuso del agua de los acuíferos, estando el 70\% de este recurso destinado al uso agrícola: Worster (1993) advierte que la agricultura irrigada será difícil de mantener por mucho tiempo, bien sea por la escasez del agua o bien por el aumento del precio para obtenerla. La presión constante del consumismo alimenta el desarrollo económico mundial, pero tiene más dificultades en satisfacer el hambre de la población. Este autor reivindica el papel de la historia en un análisis hídrico. "Es hora de que los historiadores observen más de cerca a este elemento vital de la naturaleza y las formas que ha tomado, para indagar sobre el significado del agua y su papel en la historia" (1988, p.163).

La perspectiva de la historia ambiental demuestra la certeza de la escasez de agua actual y futura debido al abuso desmedido de este recurso en nuestro tiempo, convirtiéndose en una ciencia estimuladora de diálogos entre las diferentes escalas y distintas ciencias para tratar de evitar dicha situación. 
De entre los cambios ambientales en proceso en la madre Gaya presentados por Boff y de entre las preocupaciones de Worster, elegimos el Río como motivador de la investigación debido a que creemos que su historia ambiental es un indicador relevante para comprender los cambios socioambientales en su cuenca. En ese proceso, el Río no es un elemento pasivo: busca adaptarse "naturalmente" a factores como son los ciclos hidrológicos, los cambios del uso del suelo, la deforestación, la producción de grandes plantas generadoras de energía eléctrica, los regadíos con distintas finalidades, los pequeños lagos artificiales destinados a la piscicultura, a la exploración mineral y, en definitiva, al trasvase de sus aguas, por citar los principales usos a los que las sociedades humanas, con su tecnología cada vez más creciente, lo someten (CARAMELLO, SAURI, MARÇAL, 2014; CUNHA, 2008; CUNHA, GUERRA, 2012; WORSTER, 2004).

Utilizamos un enfoque teórico y metodológico, basado en uno de los pilares de la Historia Ambiental propuesto por Worster: aquél que pretende adentrarse en identificar las percepciones, los valores éticos, leyes, mitos y otras estructuras de significado que vinculan a un individuo (o a un grupo) a la naturaleza y que también configuran a la realización de acciones sobre el mundo físico (DRUMMOND, 1991; FREITAS, 2006; GALLINI, 2004; WORSTER, 2008); Así, en esa trama el Río es el hilo conductor para reducir la distancia entre la historia de las aguas y su gestión.

La obtención de los datos se efectuó a través del uso de fuentes diferenciadas propuestas por Gallini (2004) mediante un análisis de contenido, el filtro de las informaciones pertinentes y la codificación de la información siguiendo a Miguel Verd (2015). Todo ello facilita la construcción de una serie geohistórica de hechos y percepciones.

La Historia Ambiental nos permite ampliar las fuentes de información, lo que contribuye a una mejor interpretación de los cambios geográficos. Entre las fuentes utilizadas disponemos también de páginas virtuales diversificadas, que posibilitan el acceso a datos actuales y con un mayor dinamismo en la renovación de información.

\section{EL AGUA: UN MOTIVADOR EMERGENTE DE LOS DIÁLOGOS AMBIENTA-LES INTERNACIONALES}

A lo largo de la historia, La especie humana, ha experimentado cambios adaptativos que la convertieron en una sociedad sedentaria. En esa fase el Río era reconocido como elemento esencial de desarrollo socioambiental. El acceso al agua era un desafío local: en Mesopotamia, Egipto etc se desarrollaron innovaciones empíricas y técnicas para tener acceso a este recurso antes de la era cristiana (BAINES, 1988; NACE, 1970). Hasta comienzos del siglo XX era impensable que el agua se convertiera en un factor de motivación para muchos diálogos globales y que sería tratada como uno de los principales desafíos en el siglo XXI.

\section{LA ESTRUCTURACIÓN DEL DIÁLOGO HÍDRICO: 1945 - 1999}

La bióloga Rachel Carson intentó publicar, en 1945 en la revista “Reader's Digest”, un artículo sobre las consecuencias de los pesticidas en el ambiente biológico, pero no tuvo éxito (MCINTOSH, 2007). Diecisiete años después, su libro "Silent Spring” se convertía en un clá-sico que alertó al mundo sobre los efectos de los pesticidas (MCINTOSH, 2007; SAURÍ, BOADA, 2002). Esta obra invitó a una reflexión ecosistémica, alarmada por el silencio de los pájaros y a una escala más global por la contaminación de las aguas superficiales y de los mares. A partir de Silent Spring, empezó a ser posible identificar indicadores que señalaban como todo uso y ocupación del suelo en una cuenca tiene influencia en todos los seres que habitan ese espacio y que también pueden influenciar otros sistemas por medio de la integración de los canales que integran sus aguas. Como ejemplo, la propia Carson destaca el caso de la desaparición del salmón del Río Miramichi en la costa de New Brunswick, Canadá, (CARSON, 1962).

Frente a la creciente preocupación (surgida a partir del el uso desenfrenado de los recursos naturales y la influencia de distintos factores de degradación de la cantidad y calidad del agua dul- 
ce en el mundo) la UNESCO creó el proyecto "Decenio Hidrológico Internacional" (1965), en un intento de inventariar los recursos de agua dulce mundial y desarrollar estrategias para su mejor uso. En este momento se puso de manifiesto la distribución desigual y la contaminación acelerada del agua en la era antropogénica (NACE, 1970), con los grandes desafíos que ello conllevaba.

La situación con que se enfrenta hoy día la mayor parte de la humanidad demuestra convincentemente que los problemas del hombre y de, su medio no son problemas de los hombres de las distintas naciones sino que afectan a todos los hombres y a todas las naciones. Esto se aplica especialmente al agua. La movilidad del agua es una de sus propiedades más útiles pero plantea también graves problemas tanto prácticos como científicos, internacionales como nacionales. Por lo tanto, es instructivo considerar al agua como substancia y en una perspectiva mundial (NACE, 1970, p. 10).

En ese contexto el agua pasa a formar parte de una agenda global. La primera reunión medioambiental de gran repercusión a nivel mundial se produjo en 1972 en Estocolmo, con el cambio ambiental global como tema central. Los resultados se plasmaron en forma de Principios: el primero y el segundo ponen en marcha el papel de la sociedad y el derecho que la misma posee en la construcción de la sustentabilidad socioambiental para las actuales y futuras generaciones.

Cinco años más tarde, en 1977 en Mar del Plata (Argentina) se celebró la Conferencia de las Naciones Unidas que, por primera vez en la historia, convirtió el agua el agua en el tema que guía el diálogo internacional entre los líderes del mundo en búsqueda de una gestión de dicho recurso natural. Expresamente se declaró que: "Todos los pueblos, cualquiera que sea su nivel de desarrollo o condiciones económicas y sociales, tienen derecho al acceso a agua potable en cantidad y calidad acordes con sus necesidades básicas". Es decir, en este evento el agua fue valorada como elemento natural y no solo como un recurso para el desarrollo económico, como venía sucediendo en encuentros anteriores (CASTILLO, 2009).

La creciente preocupación con el agua presentada en los eventos mundiales, pasan a concretarse en cuestiones como el contexto histórico y geográfico del acceso y la calidad del agua para la infancia y las mujeres, reconociendo la vulnerabilidad a la que se encuentran sometidos ambos colectivos y constatando la necesidad de equidad y participación de las mujeres en la toma de decisiones. La inclusión de esa pauta de género se evidencia en dos momentos distintos:

El primero, en la Convención sobre la Eliminación de todas las formas de Discriminación contra la Mujer (CEDAW), realizada en 1979, donde se amplió la discusión más allá de la dimensión económica. Esta convención entra en vigor en 1981 y garantiza a la mujer "gozar de condiciones de vida adecuadas, particularmente en las esferas de la vivienda, los servicios de saneamiento, la electricidad y el abastecimiento de agua, los transportes y las comunicaciones" (UNESCO, 2010). La discusión es retomada en Estocolmo en 1998 el Octavo Simposio del Agua, reconociendo la importante relación de género en el dialogo hídrico, mediante una mesa redonda con la temática: Contributions of women in the field of wáter resources" en el cual Rico (1988) presenta las principales reflexiones que guían el papel de la mujer en la América Latina.

i) de qué manera las mujeres en general, y los distintos segmentos que conforman la población femenina, se ven afectadas diferencialmente, en relación a los hombres, por las actuales políticas de los recursos hídricos; ii) de qué forma las desigualdades de género contribuyen a la falta de equidad e ineficiencia que afecta al sector agua; iii) cómo la potenciaciónn económica, social y política de las mujeres podría contribuir al desarrollo equitativo y sustentable de este sector (RICO, 1998, p.4)

El según momento fue dedicado al derecho de los niños, niñas y de sus cuidadores, desarrollado en la Convención de las Naciones Unidas sobre los Derechos del Niño (1990), dónde se reconoció en su artículo 24 la responsabilidad de todas las naciones en garantizar un medio ambiente en equilibrio con los niños y niñas, combatiendo las enfermedades y la desnutrición, garantizando 
el acceso el agua potable y considerando los peligros y riesgos de la contaminación, entre otros hechos (IIN, 1990).

En 1987 se organiza, por parte la Comisión Mundial sobre Medio Ambiente y Desarrollo de las Naciones Unidas, una secuencia de debates ambientales. Entre ellos estaba el uso eficiente de los recursos hídricos, destacando su uso múltiple en diversos sectores de la sociedad. El documento generado a partir de todos estos eventos se conoció como el Informe Brundtland, o "Nuestro Plan de Futuro en Común", definiéndose como el primer intento de eliminar la incompatibilidad entre el desarrollo y la sostenibilidad (BOADA; SAURI, 2002).

En 1992 se crearon dos importantes espacios de diálogo. El primero ocurrió en Dublín (Irlanda) del 26 a 31 de enero, bajo el nombre de "Conferencia Internacional sobre el Agua y el Medio Ambiente: El Desarrollo en la Perspectiva del Siglo XXI”. En ella se propusieron cuatro principios, reconociéndose por medio de ellos la urgencia de efectuar una gestión integrada de las aguas que debería ser elaborada y ejecutada de acuerdo con las leyes hídricas de cada país.

El agua dulce es un recurso finito y vulnerable, esencial para sustentar la vida, el desarrollo y el medio ambiente; El desarrollo y la gestión de aguas deberían ser basados en un enfoque participativo, involucrando usuarios, planificadores y gestores de políticas en todos los niveles; Las mujeres desempeñan un rol fundamental en la provisión, gestión, y salvaguardaría del agua; El agua tiene un valor económico en todos sus niveles de uso, y debiera ser reconocido como un bien económico. (SOLANES, GONZALEZ - VILLARREAL, 1996, p.1).

El segundo gran espacio de diálogo en 1992 se produjo durante el mes de junio en Río de Janeiro (Brasil): la Conferencia de las Naciones Unidas sobre Medio Ambiente y Desarrollo Humano, (también conocida como Río-92 paralela a la Cumbre de la Tierra 92) que fue un espacio de manifestación para todos los segmentos de la sociedad global. A través de una intensa red de diálogo entre todos los sectores de la sociedad, nació una herramienta de gestión global: la Agenda Global 21, compuesta por 40 capítulos y donde destaca el capítulo 18, que prevé el uso y protección de los recursos hídricos reafirmando que:

A água é necessária em todos os aspectos da vida. O objetivo geral é assegurar que se mantenha uma oferta adequada de água de boa qualidade para toda a população do planeta, ao mesmo tempo em que se preserve as funções hidrológicas, biológicas e químicas dos ecossistemas, adaptando as atividades humanas aos limites da capacidade da natureza e combatendo vetores de moléstias relacionadas com a água. Tecnologias inovadoras, inclusive o aperfeiçoamento de tecnologias nativas, são necessárias para aproveitar plenamente os recursos hídricos limitados e protegê-los da poluição (BRASIL, 1992).

Se puede mencionar que Rio-92 fue un punto de inflexión en el diálogo ambiental al involucrar a todos los sectores de la sociedad y, desde luego, desencadenó una secuencia de eventos ambientales tendentes a monitorizar el compromiso de los países involucrados en los acuerdos de la Agenda 21: Río + 5 (Nueva York, Estados Unidos), Río + 10 (Johannesburgo, Sudáfrica), Río + 15, o COP 15 (Copenhague, Dinamarca) hasta llegar a la Río + 20, la cual retornó a Río de Janeiro en julio de 2012.

Además, una reflexión integrada del agua pasa por tomar como base las pautas de las Conferencias Internacionales sobre la Población y el Desarrollo de la ONU. La primera se celebró en El Cairo (Egipto) en 1994 y tuvo como antecedentes un gran número de reuniones entre 1992 y 1993 así como reuniones preparatorias subregionales que involucraron a 140 países. En ella se afirmó que toda persona "tiene derecho a un nivel de vida adecuado para sí y su familia, incluidos alimentación, vestido, vivienda, agua y saneamiento" y se reconoce que la ayuda internacional se convierte esencial para alcanzar los objetivos propuestos por el evento.

1996 representa un hito en el proceso de gestión y diálogo permanente de las aguas, a través de la creación del Consejo Mundial del Agua (en inglés WWC). Su objetivo es promover la con- 
ciencia sobre el agua, creando un compromiso político y fomentando la acción en todos los niveles de la sociedad. En este mismo período el gobierno marroquí organizó el primer Foro Mundial del Agua.

El año 1997 también destaca también por dos momentos importantes: el primero fue el denominado Protocolo de Kyoto, firmado en Japón por algunos grandes líderes de la economía mundial y referido a compromisos tangibles para la reducción de los gases de efecto invernadero que, según la mayoría de las investigaciones científicas, son considerados la causa más importante del cambio climático global. En relación a nuestro trabajo, también destacaremos la aprobación de la Ley brasileña de las aguas 9.433/ 97, que se convierte en el primer instrumento jurídico a nivel nacional frente a la urgencia de la implementación de una gestión integrada del agua entre los sectores gubernamentales, los usuarios y la sociedad civil organi-zada (ANA). Esta ley sustituyó el antiguo Código de las Aguas, en vigor desde la década de 1930. Fue en esa época cuando el agua, como elemento natural y de bien público, empieza a recibir una nueva atención social, política y económica. De esta forma pasa a conocer el nuevo nombre de "recursos hídricos" y pasa a representar una alternativa al discurso antagónico previo entre desarrollo y sustentabilidad (BARLOW, 2007; MARINHO, MORETTI, 2014).

\section{LA CONSOLIDACIÓN DEL DIÁLOGO HÍDRICO EN EL SIGLO XXI: 2000 A 2015}

Los “Objetivos del Desarrollo de Milenio" (ODM) del año 2000 fueron acordados por 191 miembros de las Naciones Unidas en Nueva York y se concretaron en ocho puntos: 1 - Erradicar la pobreza y el hambre; 2 - Lograr la enseñanza primaria universal; 3 - Promover la igualdad de género y el empoderamiento de la mujer; 4- Reducir la mortalidad de los niños menores de 5 años; 5 - Mejorar la Salud Materna; 6 - Combatir el VIH/SIDA, el Paludismo y otras enfermedades; 7 - Garantizar la sostenibilidad del medio ambiente y 8 - Fomentar una alianza mundial para el desarrollo. Los dos últimos objetivos resultan esenciales para que los demás puedan tener éxito.

La Unión Europea (UE) adoptó en el mismo año la Directiva marco del agua (DMA), que es uno de los marcos compartidos de gestión de aguas (PNUD, 2006). Con un plantea-miento pionero acerca de la protección del agua, la Comisión Europea adopta las cuencas hidrográficas como unidad de gestión y propone un gran desafío: fijar el año 2015 como el año límite en que todas las aguas europeas gocen de buenas condiciones ecológicas. Ciertamente la preocupación acerca de las aguas no es reciente ya que existían Directivas previas al respecto: por ejemplo, sobre Nitratos (1991), Aguas Residuales Urbanas (1991) y sobre Agua Potable (1998). Después de la DMA se elaboraron otras leyes europeas específicas para complementar-la, relacionadas con normas de calidad ambiental y estrategia marina (2008), inundaciones (2007) y aguas de baño (2006).

El agua (o los recursos hídricos, como pasa a ser conocida el agua de forma global) se sigue fortaleciendo en diálogos internacionales s a través del Foro Mundial del Agua, que se celebra cada tres años. Este evento destaca por las alianzas globales que se han expandido desde 1996. En 2000 fue el turno de La Haya, (Países Bajos), seguido de Kioto (Japón) en 2003, la ciudad de México en 2006, Estambul (Turquía) en 2009 y la ciudad de Marsella (Francia) en 2012. En abril de 2015 se celebró en Corea del Sur el último evento, que tuvo como objetivo analizar la importancia de la ciencia y de la tecnología para hacer frente a los temas relacionados con el agua.

La ONU, para fortalecer aún más la acción global en pos de alcanzar las metas de los Desafíos del Milenio (ODM) relacionados con el agua, proclamó el periodo de 2005 a 2015 como la "Década del Agua". La fecha que se tomó como inicio fue el 22 de marzo de 2005, que a partir de entonces pasó a ser celebrado en todo el planeta como el "Día Mundial del Agua". Una estrategia que despertó interés respecto al tema en escuelas primarias y secundarias, universidades, asociaciones, ONGs, empresas, esferas gubernamentales (en escalas locales y regionales) etc. En estas fechas la educación ambiental, formal e informal, sitúa en su estrategia la diseminación de la información y en los diálogos sobre los peligros de contaminación, sequías, inundaciones y alternativas para mitigar estas situaciones (según el análisis realizado por nosotros en periódicos de Brasil, España y Portugal). 
En 2009 la ONU inaugura una agencia destinada al tema, bajo un programa denominado "ONU Agua". Junto con el resto de sus 26 agencias, comienza a establecer alianzas con organizaciones gubernamentales y no gubernamentales, para identificar y revisar cada tres años datos y tendencias que afectan los recursos mundiales de agua dulce. La misma organización a través de su Consejo de Derechos Humanos, aprobó la Resolución de 24 de marzo de 2011 en la que se manifiesta la preocupación por la ausencia de eficacia en las políticas públicas a nivel mundial sobre saneamiento básico y agua potable, que habían sido desarrolladas hasta entonces:

Profundamente preocupado por el hecho de que aproximadamente 884 millones de personas no tengan acceso a fuentes de agua mejoradas y de que más de 2.600 millones de personas no tengan acceso a mejores servicios de saneamiento, según la definición del informe de 2010 del Programa Conjunto de Monitoreo de la Organización Mundial de la Salud y el Fondo de las Naciones Unidas para la Infancia, y alarmado por la muerte, cada año, de aproximadamente 1,5 millones de niños menores de 5 años de edad y la pérdida anual de 443 millones de días de asistencia es colar a causa de enfermedades relacionadas con el agua y el saneamiento, (ONU, 2011).

Entre las alternativas para mitigar dicha situación se proponen diálogos continuos, que refuerzan el valor de los mismos a escala local e invitan a todos los sectores de la sociedad (tales como son los pueblos indígenas) a involucrarse. Sin embargo es importante reseñar el hecho de que fueran precisamente los diálogos locales los que proporcionaron al resto del mundo la conciencia de su descontento con sus realidades socioambientales existentes, evidenciando de manera objetiva que la ausencia de una gestión hídrica compromete la salud y el desarrollo económico y cultural. Es por ello que tiene gran relevancia el reconocimiento de que el conocimiento científico debe ir parejo al conocimiento de cada sector de la sociedad, tal y como se pone de manifiesto en los ejemplos siguientes de relevancia para nuestra área de estudio:

Las actividades desarrolladas localmente por el Grupo Experimental Diálogo Hídrico Multidisciplinar en la frontera entre Brasil y Bolivia, en la parte sur del Estado de Rondônia. Dicho grupo tiene entre sus actuaciones tres ediciones (2011,2013 y 2015) del "Simposio de Recursos Hídricos", cuya pretensión es socializar el diagnóstico de la realidad hídrica regional y recopilar la percepción de los distintos sectores de la sociedad, integrando a todos los acto-res en el proceso de articulación de gestión del agua en pequeñas cuencas ubicadas en la Zona da Mata en el Estado de Rondônia (CARAMELLO et al. 2015). Aunque la UNESCO en el informe de 2015 (p. 55) clasifica al continente americano como "confortable" respecto a su situación hídrica, a escala local en los diálogos publicados en la bibliografía resultante del evento podemos comprobar cómo la situación hídrica de las regiones de frontera de la Amazonia es comprometida para sus ríos, tanto en calidad como en cantidad de sus aguas.

En 2013, el Consejo Nacional de Desarrollo Científico y Tecnológico (CNPq), que tiene como objetivo contribuir a la difusión de información sobre ciencia, tecnología e innovación en Brasil, eligió el tema "Agua: retos de la sociedad” para el Premio Joven Científico. En octubre de 2014 tuvo lugar en Cáceres (España) el "Congreso Internacional de Gestión Hídrica y de Planificación Estratégica del Territorio", una iniciativa de la Liga de los Abogados Ambientalistas Mundiales en colaboración con el Ministerio de Ciencia e Innovación de España, con base en una colaboración académica entre las Universidades de Extremadura (España), Nacional Autónoma de México, Paulo Freire (Nicaragua) y de Belgrano (Argentina), entre otras. El proceso de desarrollo de la Gestión de Recursos Hídricos Iberoamericano fue el tema generador de los cinco días de evento.

El año 2015 comportó para la ONU una agenda ambiental muy activa, que comenzó el 15 de enero en Zaragoza con una conferencia con el tema "Agua y desarrollo Sostenible: de la visión a la acción”. En julio el PNUD organizó la III ${ }^{a}$ Conferencia de Financiación del Desarrollo, celebrada en Addis Abeba (Etiopia), con el foco puesto en ampliar la financiación económica, la tecnología, el conocimiento y el medio ambiente a nivel mundial. La Asamblea Ge-neral de Naciones Unidas 
tuvo lugar en septiembre en Nueva York, con la misión de aprobar la Agenda de Desarrollo Internacional para los próximos 15 años.

En diciembre de este mismo año se celebró en Paris, la vigésimo primera Conferencia de las Partes (COP21) de la Convención de la ONU sobre el Cambio Climático. Su objetivo era acordar una reducción global de las emisiones de carbono y establecer los mecanismos de apoyo a los países en desarrollo (OXFAM INTERMÓN/UNICEF-ESPAÑA, 2015). Como iniciativa de la Red Internacional del Organismos de Cuencas (RIOC) se firmó en la COP21 el Pacto de Paris, que versó sobre el agua y la adaptación al cambio climático en las cuencas de los ríos, lagos y acuíferos, suscrito por 300 organizaciones de 87 países (DONZIER, 2015). Cabe destacar que, en el informe del Desarrollo del Milenio de 2015, el objetivo siete (garantizar la sostenibilidad del medio ambiente, propuesto en 2000) ha presentado cambios positivos, ade-más de verificar que, de entre los cinco puntos definidos, tres se refieren al agua.

\section{EI RÍO Y SU PROTAGONISMO: INTEGRACIÓN HISTÓRICA ENTRE LA NATURALEZA Y LA SOCIEDAD}

Los ríos tienen un papel importante para los ecosistemas naturales y los modulados por los humanos. La percepción de su función y valor, que refleja la tabla 1, pone en evidencia su protagonismo en la determinación del origen de las aguas, en el mantenimiento de un parámetro aceptable de calidad para su consumo y en su relevancia para conseguir que el agua pueda llegar a numerosos destinos y usos. Sin embargo aún evidencia unas relaciones sociales problemáticas, aspecto que exploraremos en este apartado.

Tabla 1 - Concepto del Río.

\begin{tabular}{|c|c|}
\hline Concepto & Autor \\
\hline $\begin{array}{l}\text { Tales de Mileto creía que los ríos eran alimentados por el mar y que el viento impulsaba } \\
\text { el agua hacia el anterior de la tierra. Una vez dentro, el peso de las rocas suprayacentes } \\
\text { obligada el agua a ascender hacia las montañas, de las que surgía formando los ríos }\end{array}$ & RAYMOND L, NACE, 1970, p.26 \\
\hline $\begin{array}{l}\text { "Los ríos son corrientes de agua que se forman en las partes altas del terreno. El camino } \\
\text { que sigue un río de su nacimiento hasta su desembocadura se llama curso." }\end{array}$ & SOBREQUES, 1968, p. 46 \\
\hline $\begin{array}{l}\text { "Río antrópico y río ecosistémico como partes interdependientes de un todo: el concepto } \\
\text { de río. Este río ambiental sería el resultado de un consenso social y natural en el reconoci- } \\
\text { miento de estos componentes del medio". }\end{array}$ & VENTURA; RIBAS; SAURÍ, 2002 p. 138 \\
\hline $\begin{array}{c}\text { "Rios podem ser definidos como um amplo corpo de água em movimento, confinado em } \\
\text { um canal, e o termo é usado geralmente para indicar o principal tronco do sistema de } \\
\text { drenagem." }\end{array}$ & CUNHA, 2008, p. 219 \\
\hline $\begin{array}{l}\text { Cursos Fluviales: son conjunto de unidades eco sistémicas funcionales que, debido a } \\
\text { factores topográficos, geológicos e hidrológicos, presentan en el espacio y el tiempo } \\
\text { una anomalía hídrica positiva respecto a su medio adyacente algunas veces la presencia } \\
\text { de agua se limita a un grado notable de humedad edáfica en otros caso puede no existir } \\
\text { lámina de agua. }\end{array}$ & BOADA; JAVIER; GOMES, 2008, p. 62 \\
\hline $\begin{array}{l}\text { "Los ríos son sistemas íntimamente relacionados con los ecosistemas terrestres mode- } \\
\text { lados por el agua, y para comprenderlos es preciso tener una visión amplia, que incluya } \\
\text { aspectos muy diversos y características bien distintas." }\end{array}$ & ELOSEGI; SABATER, 2009, p.11 \\
\hline
\end{tabular}

Fuente: Elaboración propia

La concepción del río por las distintas ciencias, integran el agua y el canal metafóricamente como un cuerpo único. El agua de los ríos procede de los acuíferos, de la humedad del suelo, del agua que no puede ser filtrada por la tierra y de las precipitaciones que se dan sobre el lecho fluvial, en un ciclo constante de retroalimentación. Los ríos son también uno de los mecanismos para la evolución del paisaje terrestre, al ser agentes de erosión y transporte que remueven agua y sedimentos desde los continentes hacia los océanos (RESTREPO, 2005). 
En el balance hídrico total de la tierra, $36000 \mathrm{Km} 3$ de agua fluyen anualmente desde el interior de los continentes hacia los océanos. También se ha calculado, con base en datos numéricos de descargas fluviales, que los ríos del mundo transportan hacia el mar cerca de 19000 millones de toneladas de mate-rial, de las cuales el $80 \%$ representa el transporte o carga en suspensión (sedimentos) y el 20\% restante comprende la carga disuelta de elementos químicos y orgánicos en solución, ya sea producto del lavado de las rocas y suelos o como aporte de nutrientes, fertilizantes y contaminantes de origen humano. (RESTREPO, 2005 p. 23).

Esa dinámica solamente sería alterada en el caso de que las variables condicionantes na-turales sufrieran ciertos desequilibrios (ALMEIDA; TERTULIANO, 2012). Un río es un conector de territorios $y$, por tanto, un indicador visible de los cambios que pueden ocurrir si no existe una gestión ambiental que integre todos los usos y ocupación de una cuenca. Con una identidad propia, al igual que los pueblos, cada Río tiene una historia ambiental única, considerando que no existen dos lugares iguales en clima, relieve, geología e hidrología, así como que sobre su cuenca hay una diversidad de dinámicas culturales de apropiación de los recursos que ofrece (WORSTER, 2004).

En un estudio de caso desarrollado por Caramello (2010) entre 2008 y 2010 en la pequeña cuenca rural del Riacho d'Alincurt, ubicado en la región amazónica en el municipio de Rolim de Moura (Rondônia, Brasil), se administraron cuestionarios a 90 productores rurales. En las respuestas fue posible constatar el uso de las aguas subterráneas, respaldado por la percepción de los actores de ese espacio de que el río tenía a sus aguas contaminadas, estaba enfermo o que estaba "muy feo" para el consumo, si bien se observaba "despreocupación" acerca de las medidas para su recuperación, además de las impuesta legalmente para recuperación de la vegetación de ribera.

Se reconoce que el uso creciente del agua subterránea en el mundo está vinculado no solo a la contaminación de las aguas superficiales sino también a la distribución territorial de éstas así como de las condiciones de sequía. En un contexto dónde la demanda de las aguas superficiales es mayor que la oferta es posible ver casos fuera de la región amazónica, por ejemplo el estudio del caso de Girona, región de Cataluña/España (BRUÑOL et al, 2003). Aunque no sea un ejemplo con repercusiones globales, la opción del uso de las aguas subterráneas en la región amazónica, donde hay a priori una expresiva disponibilidad de agua superficial, puede ser un indicador de como el uso y la ocupación del suelo vienen comprometiendo las aguas de los ríos, sobre todo a los ubicados en las regiones de mayor colonización y desforestación.

Datos disponible por el Programa das Naciones Unidas para el Desarrollo (PNUD) en 2014 revelan que, de entre los desastres naturales, los del ciclo hidrológico vinculado al climatológicos y meteorológicos son los que han presentado un mayor crecimiento desde la década de 1930 hasta la actualidad (Figura 1). Este periodo culmina en lo que Bilbao y Lanza (2009) denominan "La edad de oro de la economía mundial", el periodo de 1940 hasta 1973. 


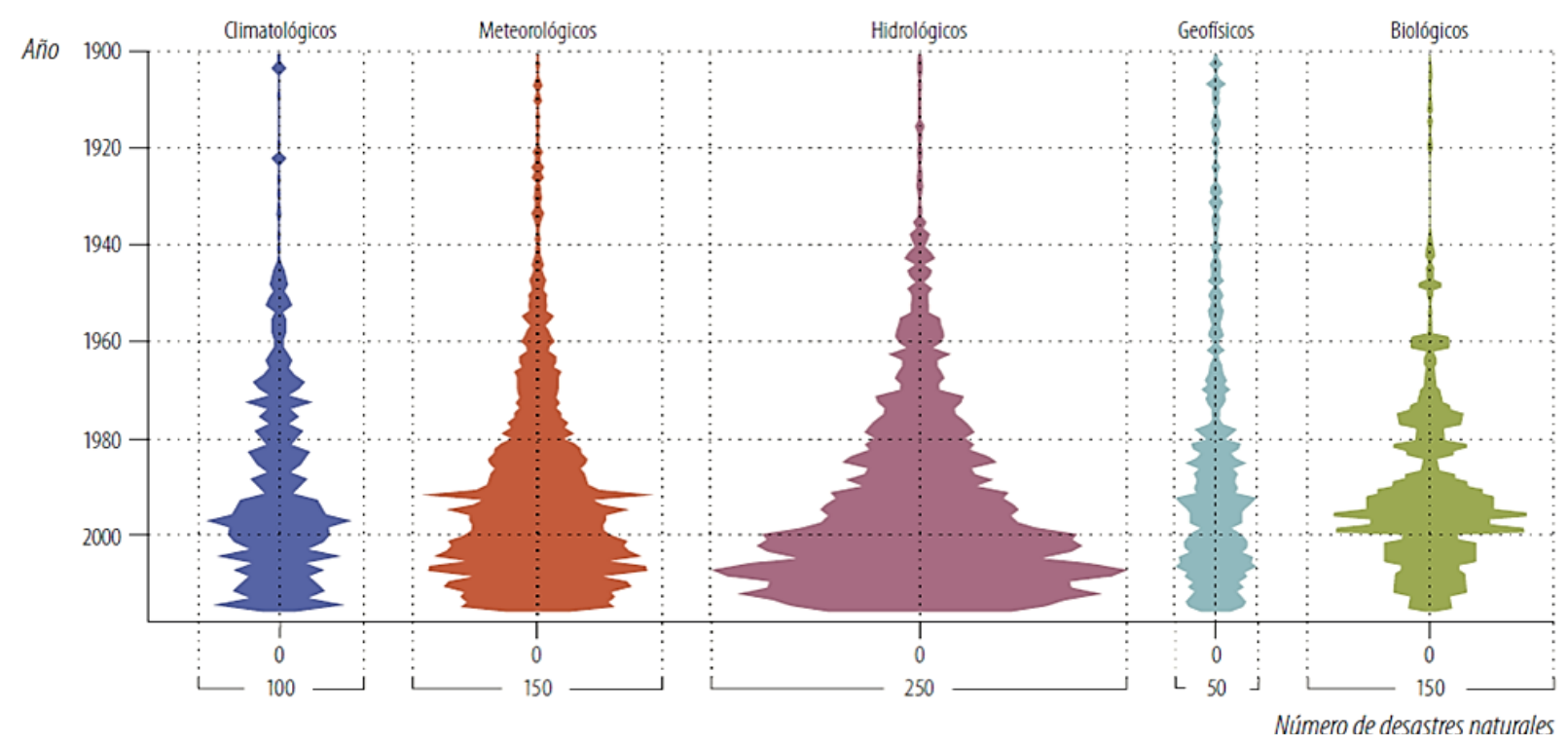

Figura 1 - Evolución de los desastres naturales de 1900 a 2000.

Nota: Los principales tipos de desastres incluyen temperaturas extremas y sequías (climatológicos), tormentas (meteorológicos), inundaciones (hidrológicos), terremotos (geofísicos) y epidemias (biológicos). Fuente: CRED 2013 in PNUD, 2014.

Un escenario que tiene al cambio ambiental como uno de sus actores. Por otro lado, el proceso se ha acelerado mundialmente debido a los procesos de cambio del uso y ocupación del suelo y de la industrialización. Las aguas superficiales presentan ya situación de escasez y el uso de las aguas subterráneas ya ha empezado a mostrar agotamiento y contaminación (TURNER, en SAURÍ; BOADA, 2002).

\section{LOS RÍOS HABLAN: EJEMPLOS DE UNA HISTORIA AMBIENTAL INTEGRADA}

\section{a) Río Nilo.}

La manifestación de respeto y dependencia con el Rio Nilo se percibe por medio de los escritos de muchos poetas, que desarrollaron "El Himno al Nilo" (figura 2), procedente de un papiro de la XIX dinastía. Con el mismo ímpetu, Ahmad Sawqi (en MARTINEZ NILLO, 2000) pone de manifestó dos características esenciales del Río: su carácter histórico, temporal, o atemporal en este caso, y su elemento primordial, el agua. En su poesía, como en la de los demás poemas que se inspiran en él, evidencia la veneración de ese río por el pueblo de Egipto (BAINES, 1988).

El Nilo es uno de los mayores ríos del mundo, cuna de la civilización occidental, como se puede apreciar en la cita siguiente; con la leyenda: "El Nilo, río sagrado de Egipto".

Fuente de vida y de prosperidad, el río Nilo fue fundamental en el nacimiento de la civilización egipcia y marcó, al ritmo de sus estaciones, la vida de quienes habitaban en sus orillas. Pese a estar situado en una de las zonas desérticas y áridas más extensas del planeta, Egipto acogió una de las civilizaciones más brillantes y ricas de la Antigüedad. Ello fue posi-ble gracias al río Nilo, que desempeñó un papel crucial en la formación y desarrollo de la cultura faraónica. Fuente inagotable de recursos, el Nilo aportó con generosidad el agua y los alimentos necesarios para la subsistencia de los egipcios, y su curso constituyó la principal vía de transporte de personas y mercancías por todo el país (Cordón, 2010, p. 34).

Ese contexto histórico nos permite concluir que el río Nilo actuó como maestro o profesor natural en el proceso de la necesaria adaptación de los pueblos ribereños a las dinámicas fluviales. Por medio de las inundaciones fertilizaba sus orillas y daba vida al desierto. De acuerdo con Muñoz-Santos y Engracia (2015), el interés científico de los griegos por entender esa dinámica 
física sobre la crecida del río es muy antiguo "Eurípides (480-406 a.C.), Heródo-to (484-425 a.C.), Esquilo (525-456 a.C.), Sófocles (496-406 a.C.) y Platón (427-347 a.C.)”. Desde la percepción de las personas, el agua que transbordaba en los periodos de subidas del río conocido como Akhet, correspondiente al período comprendido entre 15 de Julio y el 15 de noviembre era un regalo que el Río Nilo ofertaba como reconocimiento a la devoción de los pueblos que habitaban sus márgenes (CABANAS, 2015). Algo muy similar a lo que ocurre actualmente en algunas regiones de la cuenca amazónica (Brasil), como ejemplo en la relación de los pueblos ribereños con los Ríos Madeira y Guaporé.

\begin{tabular}{|c|c|}
\hline $\begin{array}{l}\text { ¿ Desde qué época riegas los } \\
\text { camnos con tus gouas? }\end{array}$ & $\begin{array}{l}\text { Lo mismo que una tela que su color } \\
\text { perdiera: }\end{array}$ \\
\hline $\begin{array}{l}\text { ¿Cuál es esa mano que colma las } \\
\text { ciudades? }\end{array}$ & $\begin{array}{l}\text { pero al llegar de nuevo, campos con } \\
\text { tus aguas? }\end{array}$ \\
\hline ¿Has bajado del cielo? & ¡Como brilla su seda de riente color! \\
\hline $\begin{array}{l}\text { ¿De alto del Edén brotaron tus } \\
\text { arroyos? }\end{array}$ & $\begin{array}{l}\text { Cada estación del año, } ; \text { oh, } \\
\text { maravilla!, }\end{array}$ \\
\hline Tus aguas desbordadas, & Va mudando la tierra de colores. \\
\hline ¿De qué nube o diluvio? & Y tan sólo Tú, Nilo, \\
\hline $\begin{array}{l}\text { ¿En qué telas tejiste el manto } \\
\text { siempre nuevo }\end{array}$ & $\begin{array}{l}\text { Eres quien va tiñendo tus vestidos. } \\
\text { Las edades quisieron agotarte, }\end{array}$ \\
\hline $\begin{array}{l}\text { ¿Desde qué época riegas los Que } \\
\text { cubre eternamente tus orillas? }\end{array}$ & $\begin{array}{l}\text { Mas tu cuna de agua aún sigue llena, } \\
\text { (.....)" (Trad. P. MARTINEZ }\end{array}$ \\
\hline $\begin{array}{l}\text { ¿Cuándo Tú te retiras queda musti } \\
\text { ajado, }\end{array}$ & $\begin{array}{l}\text { MONTÁLVEZ in MARTINEZ } \\
\text { LILLO, 2000, p. } 311\end{array}$ \\
\hline
\end{tabular}

Figura 2 - Hinno al Nilo

Fuente: Organizado por los autores con base in Martinez Lillo, 2000.

Sin embargo, los cambios ambientales resultantes de la actividad humana fueron dispares a lo largo del tiempo en el Nilo. Tomemos como modelo la gran represa de Assuã (Egipto), que posibilitó la generación de energia renovable alrededor de las tierras desérticas - cultivables en 400 $\mathrm{km}^{2}$ y el control de inundaciones, unos cambios positivos. No obstante, ello ocasionó también la disminución de la fertilidad de sus márgenes aguas abajo, la disminución de los bancos de anchoas y peces, aparte del desplazamiento de 90 mil campesinos egipcios y nubios y de la destrucción de patrimonios históricos (ALTMAN, 2004).

En respuesta a esos cambios ambientales, en enero de 2015 el presidente egipcio Abdel-fatah al Sisi hizo un pronunciamiento referente al "Documento del Nilo": "Como presidente y ciudadano de Egipto, inauguro la campaña popular para salvar el río Nilo y anuncio mi adhesión al Comité de los Guardias del Nilo para protegerlo de la contaminación y las infracciones, y preservar la única fuente de vida del país", subrayó el mandatario durante el acto" (Agencia FE, 2015).

\section{b) Río Muga.}

El río Muga, ubicado en la provincia de Girona (España), ha presenciado los primeros conflictos sociales derivados de la gestión de este recurso hídrico cada vez más apreciado por su escasez (VENTURA, RIBAS, SAURÍ, 2000). El estudio desarrollado por Bayés, Ribas y Sauri (2003) expone el comportamiento histórico de las sequías en esa región, a partir de las informaciones recopiladas por la prensa regional en el espacio temporal de 49 años, con análisis realizados para intervalos de 5 años (Cuadro 1). 
CARAMELLO, N.; SAURÍ, D.

Cuadro 1 - Evolución cronológica del número de noticias según ámbitos temáticos relacionados a la gestión del agua

\begin{tabular}{|c|c|c|c|c|c|c|c|}
\hline & \begin{tabular}{|c|}
$\begin{array}{c}\text { Abastecimiento } \\
\text { de agua }\end{array}$ \\
\end{tabular} & $\begin{array}{c}\text { Saneamento } \\
\text { Básico } \\
\end{array}$ & $\begin{array}{c}\text { Impacto } \\
\text { Ambiental } \\
\end{array}$ & Contaminación & $\begin{array}{c}\text { Estado } \\
\text { hidrólogico } \\
\end{array}$ & $\begin{array}{c}\text { Meteorologia } \\
\text { extrema }\end{array}$ & Total \\
\hline $1951-1955$ & 3 & 0 & 0 & 0 & 2 & 7 & 12 \\
\hline $1956-1960$ & 3 & 0 & 0 & 0 & 0 & 8 & 11 \\
\hline $1961-1965$ & 9 & 0 & 1 & 0 & 0 & 6 & 16 \\
\hline $1966-1970$ & 0 & 1 & 0 & 1 & 2 & 4 & 8 \\
\hline 1971-1975 & 6 & 3 & 1 & 0 & 1 & 1 & 12 \\
\hline 1976-1980 & 7 & 5 & 1 & 4 & 1 & 4 & 22 \\
\hline 1981-1985 & 12 & 2 & 0 & 9 & 9 & 21 & 53 \\
\hline 1986-1990 & 43 & 20 & 13 & 10 & 12 & 7 & 105 \\
\hline 1991-1995 & 35 & 16 & 6 & 2 & 10 & 8 & 77 \\
\hline $1996-2000$ & 42 & 6 & 18 & 1 & 14 & 10 & 91 \\
\hline Total & 160 & 53 & 40 & 27 & 51 & 76 & 407 \\
\hline
\end{tabular}

Fuente: BAYÉS; RIBAS; SAURÍ, 2003.

Hasta el año 1971 los principales cambios en la cuenca del Rio Muga se atribuían a factores físicos. Luego surgieron las primeras preocupaciones respecto al abastecimiento de agua, que permanecieron como asunto principal hasta 2000. A partir de 1976 la preocupación con el abastecimiento de agua, saneamiento básico, impacto ambiental y contaminación aparece cada vez más frecuentemente. Entre 1986 y 1990 se produce el periodo con mayor número de noticias vinculadas a los indicadores analizados, aunque los factores naturales siguen evidenciándose, destacando el estado hidrológico a partir de 1981.

\section{c) Rio Tordera.}

El periódico "El País”, noticia “El Tordera, un río envenenado entre Gerona y Barcelona”, en 1979, evidenciando la preocupación de los Alcaldes de nueve poblaciones vinculada directamente con el río en cuestión, con la contaminación del dicho cauce fluvial, con la disminución de la calidad del agua de los pozos y la gran cantidad de cloro que era necesario para convertir el agua en potable (RAMON, 1979).

Los contaminantes provenían de los afluentes que desaguan en el río Tordera, con usos variados entre agricultura, industria y residencias. 36 años después, la realidad ambiental del río sigue preocupando y rellenando páginas de los periódicos locales, como ejemplo: "El pueblo del Montseny vierte aguas residuales al río Tordera", problema que involucra la Agència Catalana de l'Aigua (ACA), La Coordinadora per la Salvaguarda del Montseny (CSM), Ayuntamiento de Montseny (Vallès Oriental) y ecologistas en un proceso de solicitud de la implantación de una gestión adecuado de saneamiento en el pueblo con reflejo en el interior del Parc Natural del Montseny (LA VANGUARDIA, 13/08/2014).

Otro estudio de caso destacable, porque presenta un cambio ambiental "positivo", ocurre en la cuenca del río Tordera, en el valle de d'Olzinelles. En este valle se produjo una disminución de población, que pasó de 179 a 26 habitantes entre 11924 y 2006. Como consecuencia, sin el uso y la ocupación del suelo transformando el paisaje, los bosques se amplíiaron de 988.44 ha (1956) a 1042.32 ha (2002), la actividad agrícola se redujo de 114,55 a 42,15 ha, y la plantación de árboles en la ribera aumentó de 7,08 a 19,13 ha. Ese cambio proporcionó un mayor flujo del agua y la revitalización de las riberas. No obstante, el nuevo escenario no evitó la extinción de la especie Arvicola sapidus, popularmente conocida como rata del agua. Según Otero et al (2008), la extinción de esta especie es un indicador de que los cambios globales influencian en los demás sistemas naturales locales, hecho que debe valorarse en las pautas de diálogos ambientales mundiales. Sin embargo también pone de relieve el papel del cambio local frente a las transformaciones mundiales. 


\section{d) Rio Matarraña.}

Un pequeño afluente que, sin embargo, motivó uno de los conflictos más agudos vividos en la Cuenca del Ebro (España). Fue el protagonista de la urgencia con que los pueblos que la habitan (Comunidades Autónomas de Aragón y Cataluña y en su parte alta también limita con la provincia de Castellón en la Comunidad Autónoma de Valencia) tenían por cambiar el uso y la ocupación de su cuenca firmando compromisos de recuperación de los ríos locales. En 2008 se realizó un estudio previo de los principales problemas, que son comunes a los territorios que componen la cuenca, buscando una nueva configuración para el Plan Hidrológico de la Cuenca y adaptándolo a la normativa europea que entró en vigor en 2000.

De esa manera, las consecuencias de los cambios ambientales (en el curso de su configuración histórico-socio-ambiental) serían el vector del diálogo e intermediación social, posibilitando a la implantación del "Contrato para el río Matarraña", en 14 de febrero de 2011 en el Ayuntamiento de Calaceite, promoviendo un movimiento ciudadano por la "Nueva Cultura del Agua (CASAJUS, 2015). El "Contrato de Río" tienen su origen en Francia y se remontan al año 1974, como resultado de las iniciativas locales del programa "ríos limpios" promovidas por el actualmente denominado Ministerio de Medio Ambiente francés (CAMPOS et al, 2010). El Contrato de Río es una metodología participativa que reúne a todos los actores para cooperar en todo lo relativo al río. Más concretamente se dan cita las administraciones públicas implicadas, asociaciones de regantes, asociaciones empresariales, educativas, etc. En 2015 participaron 33 entidades representativas, públicas y privadas (MONGES, 2015).

\section{e) Río Rin.}

Uno de los más importantes de Europa, que atraviesa nueve países y es un relevante ejemplo de que el diálogo hídrico con implantación de acciones conjuntas es imprescindible. Holanda fue la precursora de la lucha por conseguir acuerdos diplomáticos que pudiesen recuperar la vida del río Rin, que sufrió una restricción total de pesca y de su acceso directo al consumo debido a un alto índice de contaminación desde 1884 y que continuó en ascenso durante el siglo XX.

Ya desde 1950 los Gobiernos de Holanda, Alemania, Francia, Luxemburgo y Suiza acordaron la creación de la "Comisión Internacional para la Protección del río Rin - IKSR". Pero fue solo después de la catástrofe de la empresa Sandoz ubicada en Basilea (Suiza) en 1986, con el vertido de una gran cantidad de productos químicos en el río que ocasionó una catástrofe ambiental en todo el curso río, cuando se crea la "Conferencia Extraordinaria de Ministros" y se establece los programas de acción (BAUMANN, 2008).

La Conferencia además encargó a la IKSR elaborar un "Programa de Acción para el Rin", con el fin de asegurar el suministro de agua potable en el futuro, establecer un sistema de alerta temprana de siniestros y reducir la contaminación por sedimentos en el delta. El Programa se dividió en tres fases: Fase 1 (1987-1989): Formulación de una lista con sustancias prioritarias; Fase 2 (1989-1995): Llevar a cabo las medidas acordadas, e implementarlas según el principio del "Estado de la técnica"; y, Fase 3 (19952000): Evaluación de logros y establecer posibles medidas adicionales (BAUMANN, 2008, p. 22).

\section{f) Los Ríos de la márgenes derecha del Río Amazonas.}

Las cuencas de los ríos Xingu, Tapajós, Madeira, Purus, Juruá, Jutaí y Javari (Brasil) forman parte de un proyecto pionero: el "Plan estratégico de recursos hídricos de los afluentes de la margen derecha del río Amazonas (PMDA)" desarrollado por el ANA, la Agencia Nacional de las Aguas del Brasil. Estas cuencas ocupan un área de 2,54 millones de $\mathrm{km}^{2}$ (Figura 3), conformando un complejo hídrico que, según la ANA (2012), puede ser dividido en dos grupos: 
CARAMELLO, N.; SAURÍ, D.

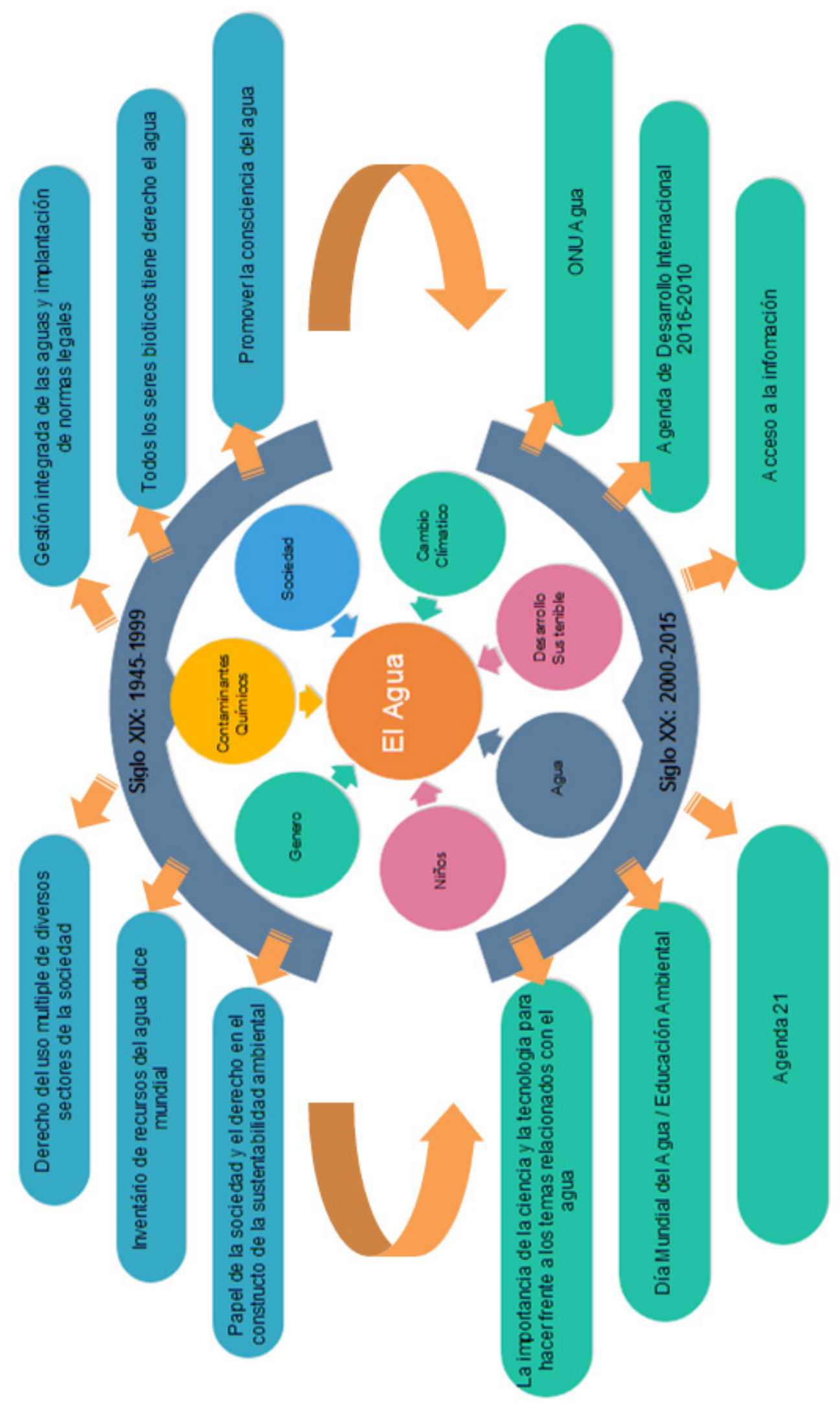

Figura 3 - Principales fuentes de polución en los afluentes de la margen derecha del Amazonas Fuente: ANA, 2012 
1. Aquele formado pelas Bacias do Xingu, Tapajós e Madeira, onde a presença humana e a atividade económica esta irreversivelmente consolidada, na totalidade ou em parte.

2. Aquele que reúne as Bacias do Purus, Juruá, Jutaí e Javari, nas quais a presença humana se mostra significativamente mais rarefeita.

La rápida transformación del paisaje amazónico por medio de una urbanización acelerada, el avance de la industria agropecuaria, la implantación de industrias y empresas mineras etc, son también indicadores de que la metodología de ocupación territorial (donde el término "sustentabilidad hídrica" se ha idealizado en los principales diálogos ambientales mundiales del siglo XX y XXI) y las observaciones que buscan que los recursos hídricos sean un derecho de todos, siguen siendo perfectos teóricamente pero quedan lejos de una aplicación real. Un ejemplo claro lo tenemos en cómo la ausencia o escasa implantación de un sistema de saneamiento básico viene comprometiendo la calidad de los ríos monitoreados por el MDA.

Urguell y Rubiolo (2008) afirman con base en la experiencia española, que al largo del siglo XX las poblaciones ribereñas han ido abandonado gran parte de los usos tradicionales de los ríos, fines como bañarse, pescar o hacer excursiones pasan a ser cada vez menos frecuentes, debido a la degradación del medio fluvial. Sin embargo no es una realidad que puede aplicarse a todos los pueblos: incluso ante la posibilidad de contaminación, el río es la única posibilidad de acceso el agua en muchos casos, lo que impide el distanciamiento del mismo. El caso de los pueblos que viven en sus márgenes y que se encuentran en esta situación es posible analizarlo en el testimonio de un ribereño del río Madeira-Rondônia/Brasil.

O meu nome Lourimar, significa aquele que carrega os louros conquistados no mar. Não tenho o mar, mas o rio em frente ao meu local de trabalho e eu acho que o rio não é para mim. Eu acho que o rio é para a região... o rio é a vida da região... porque se nós tivéssemos o rio... nós não temos nada.... o nosso é a nossa estrada.... é onde se tira o alimento do pessoal...é onde nós nos divertimos. O rio é tudo... Aqui o rio é tudo .... (SILVA, 2000, p. 111).

La historia ambiental de estos ríos es muy similar a los demás ríos del planeta, la mayor parte de los cuales se hallan desvinculados de una propuesta de desarrollo integrada y compatible con las políticas públicas de sustentabilidad. Consiguiendo que los actores hidrográficos "hablen" en nombre de los ríos, se pueden inferir presentar los cambios en las dinámicas hidrológicas antropogénicas.

\section{REFLEXIÓN}

Fue el gran impacto de la reflexión sobre las consecuencias del desarrollo económico moderno (en la sensata exposición de Rachel Carson) el detonante de que la historia del ambiente hídrico (integrando los usos de la cuenca) se convirtiera en objeto de interés y estudio por parte de las ciencias humanas y naturales y pasase a integrar una década después los diálogos internacionales, en busca de una metodología eficaz para una gestión sostenible de los recursos hídricos.

El agua tuvo un papel de agente emergente (desde la implantación del diálogo hídrico hasta su consolidación) retratando la urgencia y necesidad de directrices que cambiasen la realidad identificada mundialmente, al tiempo que se convertía un símbolo de lucha en medio de intereses difusos y reafirmaba su presencia en documentos gubernamentales y numerosos acuerdos. Worster (1985), alega que muchas veces el agua fue valorada más como una mercancía como que un bien común reconocido en leyes nacionales (como la 9.433/97 que rige a respecto de una política del Agua en Brasil). El asunto de los recursos hídricos consolida su presencia en las negociaciones en todas sus vertientes, aunque sigue existiendo a nivel local (en la gente que vive en las márgenes de los ríos) una falta de sensibilización con esas nuevas estrategias de gestión de un bien tan esencial para su propia supervivencia y que forma parte de su quehacer cotidiano. 
Teniendo en cuenta que las cuencas hidrográficas internacionales cubren casi la mitad de la superficie de la tierra del planeta (PNUD, 2014) es incuestionable la relevancia de los foros de discusiones ambientales - creados de 1945 a 2015 - para la consolidación de una política del agua mundial. Todavía, es necesario reconocer a través de la historia ambiental de los ríos que el metabolismo económico siguió su expansión paralelamente a las llamadas a una sociedad sostenible, haciendo inviable la eficacia de los acuerdos mundiales y generando desigualdades de acceso y derecho al agua.

En síntesis, las principales pautas socioambientales, que desencadenarían los diálogos ambientales y el derecho el agua en los 71 años de diálogos pueden ser enumerados: los derechos de género y de la infancia, el desarrollo económico, el cambio climático, los cambios en la sociedad, la contaminación y la propia agua. Para todo ello, se crearon instrumentos de intervención.

En los últimos 71 años se vienen ampliando las líneas de discusión e intervención: se generan leyes hídricas, se abre la posibilidad de participación de todos los sectores de la sociedad, se prioriza teóricamente la necesidad de garantizar los principios de calidad y cantidad para todos los pueblos y para el mantenimiento de los ecosistemas locales y se crean nuevos espacios de discusión permanente como la Agenda 21 y el ONU Agua. Sin embargo la aplicación de la Agenda 21, que posibilita una gestión integrada y el derecho de acceso a la información ambiental y de la calidad hídrica, son dos instrumentos que necesitan evolucionar, especialmente en el Estado de Rondônia, donde evidenciamos su ausencia.

Es necesario reflexionar acerca de cómo el desarrollo económico ha seguido siendo un talón de Aquiles en la aplicación de las medidas adoptadas, de forma que los resultados obtenidos han sido menos eficaces. El avance de la degradación de las cuencas de la margen derecha de la Amazonia es un ejemplo de cómo el gran interés por las aguas superficiales de ese reservorio no frenó los incentivos internacionales económicos perniciosos para los cambios ambientales, que hoy hacen más frágil dicho ecosistema, (por ejemplo el incentivo internacional para la producción de cereales y oleaginosas).

El Río, uno de los principales vínculos de la sociedad con el agua, se mantuvo durante mucho tiempo oculto. La manera de exponerlo a los foros de la discusión pública fue la decisión de considerar - a través de acuerdos internacionales - la cuenca hidrográfica como una unidad de gestión, reconociendo que todo uso y ocupación en su territorio interfiere en la calidad y cantidad de las aguas. A pesar de suponer un salto extremamente significativo para la ubicación de las aguas en su merecida posición, el rio todavía siguió oculto en muchas facetas del diálogo. La propia historia de algunos ríos mundiales, citados en el presente texto, nos ayuda a reflexionar y entender acerca de la relevancia de los mismos en un proceso de interacción de todos los sectores de la sociedad: en un dialogo a escala local donde muchos otros ríos podrían ser citados en diferentes escalas geográficas.

El río Matarraña, en España, es un ejemplo que el diálogo de la aguas necesita asentarse, para que los actores hidrográficos asuman la responsabilidad de cambiar el uso y ocupación de la cuenca en busca de una mejora de la calidad de las aguas a corto, medio y largo plazo. Como los demás ríos citados, ello permite asegurar la inserción del Río como protagonista directo de un plano de gestión hídrica, aproximando a la misma los actores y favoreciendo un desarrollo económico dentro del principio de sustentabilidad que propone el informe Brundtland.

Las aguas son un visitante pasajero y, ciertamente, son un indicador de cómo el uso y ocupación de una cuenca puede comprometer la economía, la salud y la cultura de un pueblo. Pero los ríos seguirán siendo los compañeros de viaje de las civilizaciones que construyen la historia. Son ellos los que indican cuestiones físicas, como el grado de explotación de las aguas superficiales o la compactación del suelo al recibir una descarga pluvial mayor de la habitual (cuando en la verdad debería s infiltrarse en el subsuelo), pero también reflejan la ausencia de compromiso de la sociedad en su salvaguarda, por ejemplo cuando sus aguas son utilizadas como depósitos de residuos sin tratamiento desde las redes urbanas o cuando reciben una gran cantidad de productos químicos utilizados en la agricultura y la ganadería. 
En ese sentido creemos que es relevante incidir en las pautas que salgan de los foros de diálogo mundial, donde las responsabilidades puedan ser compartidas entre actores globales y los actores locales. Sobre esa última afirmación Bauman (2008) expone a respecto del río Rin que "la gente a lo largo del Rin tiene gran afinidad con el río, lo llaman "Padre Rin"; ello, posiblemente de manera inconsciente, ha apoyado los esfuerzos para recuperar esta gran he-rencia cultura (BAUMAN, 2008 p. 111), algo similar al río Nilo y río Madeira, donde el contacto con el río influye en la sociedad, humanizando su relevancia y compartiendo la responsabilidad de mantenerlo saludable.

\section{CONCLUSIONES}

Al diseñar un estudio de gestión del agua deben tenerse en cuenta los retos a los que éste instrumento se enfrenta. Es aconsejable, desde un punto de vista geográfico, considerar que las aguas no se distribuyen de forma proporcionada y que no son accesibles por igual en todo el mundo, tanto por razones naturales (clima, la vegetación, el suelo, la altitud, longitud, etc.) como humanas (la cultura, la economía, la política pública, etc.). Son esos factores los que condujeron al Informe del Programa de Desarrollo de las Naciones Unidas para el Desarrollo - PNUD en 2006, a clasificar el agua como recurso limitado en gran parte de Oriente Medio, África, partes de América Central y el oeste de Estados Unidos. La predicción indica también que, probablemente en el 2050, más de $45 \%$ de la población mundial carecerá de acceso el agua potable (PNUD, 2006) si no se interviene adecuadamente para minimizar dicho riesgo.

América del Sur está, dentro del informe citado, entre las zonas más ricas en recursos hídricos del planeta, con énfasis en Brasil, que tiene aproximadamente el 20\% de las reservas de agua dulce del mundo. La región amazónica concentra el 60\% del territorio brasileño con menor densidad de población, pero con el $80 \%$ del agua dulce, mientras que el $20 \%$ restante está distribuido entre las regiones Sur, Centro Oeste, Nordeste y el Sudeste, donde los conflictos por agua van en aumento desde la década de 1970 En contra de lo que a primera vista pudiera parecer, el porcentaje de agua dulce en la región amazónica en la actualidad no es un factor que permita ser optimista: muchas zonas carecen de cursos fluviales de entidad lo que, unido a la falta de agua para uso doméstico, refuerza la necesidad del diálogo local en aras de entender históricamente las "oscuras razones" que han derivado en el escenario actual y desencadenar acciones que mitiguen la nada utópica realidad que se ha identificado en varias cuencas fluviales en Rondônia.

Como ya hemos mencionado, los ríos hablan por medio de la calidad y cantidad de sus aguas. Conocer los contextos históricos de sus cambios ambientales puede ser un punto de partida para las intervenciones actuales necesarias. Después de 71 años de diálogos hídricos, el pasado convierte se hoy nuestro mayor profesor o maestro. Y ese profesor o maestro nos enseña los ambientes naturales transformados en objeto de estudio, lo cual es una invitación a poner en funcionamiento la base teórica de la historia ambiental y su metabolismo social, como una lupa de aumento que permite comprender los procesos que desencadenaran los escenarios múltiples (y en diferentes escalas de intereses) observables por cada equipo de investigación.

Identificar el origen del agua en una pauta de diálogo significa posibilitar que su identidad sea reconocida con la relevancia que merece; es permitir el protagonismo histórico que representa en el lugar en el que se ubica. Si buscamos integrar de facto todos los actores en una gestión de cuenca hidrográfica de las aguas superficiales fluviales, se hace necesario reco-nocer que la historia ambiental puede convertirse en un instrumento de gestión fundamental.

\section{REFERENCIAS}

AGENCIA EFE. El presidente egipcio firma un documento para proteger el río Nilo. EFEEl Cairo23 abr. 2015. 
ALMEIDA, Josimar Ribeiro; TERTULIANO, Marcos Faria. Diagnose dos Sistemas Ambientais: Métodos e Indicadores. Cunha, S. B, Guerra, A. J. T. (org.) Avaliação e Pericia Ambiental. 12 ed. Rio de Janeiro: Bertrand, 2012. p. 115-172

ALTAMANA, Max. Hoje na História - 1990: É construída a represa de Assua, a maior do rio Nilo. Sao Paulo: Uol, 21 de julio de 2014.

BAINES, J. Ç. El Gran Río del tiempo: Egipto vivía el ritmo de las crecidas del Nilo. El Correo/Unesco, ano XLI, 1988. 40p.

BARLOW, M. El Agua Nuestro Bien Común. The Commons - onthecommons.org / The Council of Canadians, 2007. 45p. Accedido 15 junio 2014.

ANA. Plano Estratégico de Recursos Hídricos dos Afluentes da Margem Direita do Rio Amazonas PER-MDA. Brasilia, Distrito Federal, 2012. 404p.

BAUMANN, J. ALEMANIA: Manejo del agua en la cuenca transfronteriza del río rin. Primer coloquio jurídico internacional sobre regulación y manejo integral de los recursos hídricos. Comisión Nacional del Agua: Síntesis de Ponencias. México 2008. pp. 21-23.

BRASIL. Agenda 21 Global. Ministerio del Medio Ambiente. 1992.

BOADA, M; JAVIER G. F. Biodiversidade. Girona: Editora Rubens, 2008. 176p.

BOADA, M; SAURI, D. El Cambio Global. Barcelona: Editora Rubens, 2002. 144p.

BOFF, L. Todos en guerra contra Gaya. Site: Leonardo Boff. 2009.

CABANAS, A. El secreto del Nilo. Barcelona: S.A. Ediciones B., 2015. 830p.

CARAMELLO, Nubia; SAURÍ, David. P; MARÇAL, Monica. In CAVALCANTE, Madalena (org). Contribuição Teórica Metodológica do estudo da história ambiental e da geomorfologia ambiental na leitura integrada de uma Bacia Hidrográfica. In Gestão Ambiental: Desafios e Possibilidades. Curitiba: Editora CRV, 2014. p 55-80

CARAMELLO, N. Elementos para Gestão dos Recursos Hídricos do Igarapé D’Alincurt. Disertación de Máster. Universidad Federal de Rondônia - Brasil, 2010.

CARAMELLO, N; PENHA, M; SAURÍ, D. P et al. - Indicadores de insustentabilidade hídrica na Amazônia: mobilização de todos os setores para implantação da gestão das águas no estado de Rondônia - Brasil.

Revista Científica Monfragüe Desarrollo Resiliente: 66-88. Volumen IV, No 2 en abril de 2015.

CASTILLO, Los Foros del Agua: del Mar del Plata a Estambul 1977 - 2009. Documentos de Trabajo No 86. Consejo Argentino para las Relaciones Internacionales. 2009.

CARSON, R. Primavera Silenciosa. Edición y traducción de ROS, Joandoménec. Barcelona: Editorial Crítica, 1962. 372p.

CORDÓN I Sola-Sagalés. El Nilo, el río sagrado de Egipto. Historia de National Geographic nº 77, 2010. COMISIÓN EUROPEA. Directiva Marco Del Agua. Informe España, 2000. Disponible en: <www.directivamarco.es >. Accedido en: 30 diciembre 2013.

COMISIÓN EUROPEA. Objetivos de Desarrollo del Milenio Informe de 2015. España, 2015. Disponible en: < http://www.un.org/es/millenniumgoals/pdf/2015/mdg-report-2015spanish.pdf $>$. Accedido en: 30 noviembre 2015.

CUNHA, S. B; GUERRA, A. J. T Avaliação e Pericia Ambiental. 12 ed. Rio de Janeiro: Bertrand, 2008. $286 \mathrm{pp}$

CUNHA, S. B. Canais fluviais e a Questão Ambiental. In Cunha, S. B y Guerra, A. J. T (eds). A Questão Ambiental Diferentes Abordagens. Rio de Janeiro, Brasil: Bertrand Brasil, 2008. pp.219 - 238.

DONZIER, Jean-François. COP21: A MÁS DE 300 ORGANIZACIONES DEL MUNDO ENTERO HAN FIRMADO EL PACTO DE PARÍS SOBRE EL AGUA Y LA ADAPTACIÓN AL CAMBIO CLIMÁTICO EN LAS CUENCAS DE LOS RÍOS, LAGOS Y ACUÍFEROS. Rede Internacional de Organismos de Cuenca (RIOC). 2015.

ELOSEGI, Arturo; SABATER, Sergi. Conceptos y Técnicas de Geormorfologia Fluvial. Bilbao: Editora Rubens, 2009. 462p. 
FREITAS, I. A. História Ambiental e Geografia. XII Encontro Regional de História: Usos do Passado. Niterói: ANPUH-RJ, 2006. pp. 1-9.

GALLINI, S. Problemas de métodos en la Historia Ambiental de America Latina. Penúltima versión entregada para publicación en el Anuario IHES (Argentina), 2004. pp. 147-171.

GUERRA, A. J. T, MARÇAL, M. S. Geomorfologia Ambiental. Rio de Janeiro: Bertrand Brasil, 2006. 192p. IIM, Instituto Interamericano del niño (1990). Comentarios a la Convención de las Naciones Unidas sobre los Derechos del Niño.

MARINHO, V. L.F \& MORETTI, E. C Água: Entre Dilemas de Disputas: Uma Experiência na América Latina. 2014. spn (doc 15p).

MARTíNEZ, Lillo, R. I. Egipto, en três dimensiones. Philologia Hispalensis, 14 fasc: 309-316, 2000. MCINTOSH, Phyllis Una mujer apacible cuyo libro habló en voz alta. Rachel Carson: La Pluma contra El veneno. 2007. p. 1-4.

MOLINA, M. G; TOLEDO, M. V. Metabolismos, Natureza e Historia: Para Uma Teoría de Transformações Sócio Ecológica. Barcelona: Editora Icaria, 2011.375p.

MONGE, Cristina. 2015: Water Annual International Zaragoza Conference. Disponible en: < https:// fromvisionto act ion.wordpress.com/2015/01/08/contratos-de-rio/>. Accedido en: 1 noviembre 2014.

NACE, Raymond L. El Agua y el hombre: panorama mundial. UNESCO - El Decenio Hidrológico Internacional, 1970. 47p.

ORGANIZACIÓN DE LAS NACIONES UNIDAS. Programa para El Desarrollo - PNUD. Relatoría del Desarrollo Humano. 2006.

ORGANIZACIÓN DE LAS NACIONES UNIDAS. Programa de las para El Desarrollo - PNUD. Informe del Consejo de Derechos Humanos. 2011.

ORGANIZACIÓN DE LAS NACIONES UNIDAS. Más allá de la escasez: Poder, pobreza y crisis mun-dial del agua. 2014.

ORGANIZACIÓN DE LAS NACIONES UNIDAS. Relatório do Desenvolvimento Humano. 2013.

ORGANIZACIÓN DE LAS NACIONES UNIDAS. Informe sobre Desarrollo Humano 2014: Sostener el Progreso Humano: Reducir vulnerabilidades y construir resiliencia. 2014.

OXFAM INTERMÓN / UNICEF-ESPAÑA. España frente a los retos de la Agenda de Desarrollo Sostenible. 2015.

RAMON, Sole. El Tordera, un río envenenado entre Gerona y Barcelona. EI País/Archivo, 20 junio de 1979.

RESTREPO, J. D. A. Los sedimentos del río Magdalena: reflejo de la crisis ambiental. Fondo Medellín, Colombia: Editorial Universidad EAFIT, 2005. 270p.

RICO, M. N. Las Mujeres En Los Procesos Asociados Al Agua En América Latina. Estado de Situación, Propuestas De Investigación Y De Políticas. "Stockholm Water Symposium. Workshop n 8:"Contributions of women in the field of water resources", 1998. 18p.

SILVA. J. d' C. O Rio, A Comunidade e o Viver. Tese de Doctorado. Departamento de Geografia - Universidade de São Paulo: USP. 2000. 181p.

SOBREQUES, S. España Geográfica. Barcelona: Editorial Teide S.A, 1968.

UNESCO. EL AGUA EN UN MUNDO EN CAMBIO. 3er Informe de las Naciones Unidades sobre el desarrollo de los recursos hídricos en el mundo. 2009. (Impreso).

UNESCO. Protocolo Facultativo de la Convención sobre la eliminación de todas las for-mas de discriminación contra la mujer. Observaciones finales del Comité para la Elimina-ción de la Discriminación contra la Mujer a la República de Panamá (1998 y 2010), 2010.

UNESCO. Urge una gestión más sostenible del agua según un nuevo informe de las Naciones Unidas. 2015.

URGUELL, Arnau, RUBIO, Marta. El Marc socieconòmic de La conca de La Tordera. In BOADA, Martíns; MAYO, Sílvia; MANEJA, Roser (eds). Els Sistemes Socioecolòligics de la Conca de la Tordera. Barcelona: Institució Catalana d'Història Natural. España, 2008. 
VENTURA, M. P., RIBAS, A. P., SAURÍ, D. Dos discursos Antagônicos a la Gestión Integral de los Ríos: El Río Antropocéntrico Versus el Río Ecocéntrico. Estudios Geográficos LXIII, 246, 2002. p. 119-141.

WORDOMETERS. Datos estadísticos dinámicos en tiempo real. Disponible en: $<\mathrm{http} / / \mathrm{www}$.worldometers.info/br/> . Accedido en: 27 octubre 2015, a las 01:12.

WORSTER, D. Rivers of Empire: Water, Aridity, and the Growth of the American West. Oxford University Press. New York, 1985. 416p.

WORSTER, D. The Wealth of Nature - Environmental History and the Ecological Imagination. Oxford University Press. New York/Oxford, 1993. p. 123-134.

WORSTER, D. Doing Environmental History. The ends of the Earth - perspectives on moder environmental history. Traducido por José Augusto Drummond do original, Cambridge University Press, 1988. p. 289-307.

WORSTER, D. Por qué necesitamos de la historia ambiental? En libro. Revista Tareas, n. 117, mayo-agosto. CELA, Centro de Estudios Latinoamericanos, Justo Arosemena, Panamá, R. de Panamá, 2004. p. 119-131.

Trabajo presentado en agosto 2016 Trabajo aceptado en septiembre 2016 